\title{
Evidence-based primary health care and local research: a necessary but problematic partnership
}

\author{
Stephen Abbott ${ }^{1}$, Jane Bickerton ${ }^{1,2}$, Mary-Louise Daly ${ }^{2}$ and Sue Procter ${ }^{1}$ \\ ${ }^{1}$ City Community and Health Sciences, City University, London, UK \\ ${ }^{2}$ Diplomierte Pflegefachfrau, University Hospital, Basel, Switzerland
}

\begin{abstract}
Background: Front-line NHS staff undertake small research projects to answer questions about local patients and services, but these projects often face considerable challenges. This paper reports on one such project. Aims and methods of study: The study used structured interviews in order to find out about the knowledge of nutrition among Bangladeshis using an NHS Walk-in Centre. Development of the study: Time constraints posed considerable difficulties in progressing and completing the study; flaws in the methodology emerged; and underpinning assumptions about health promotion and ethnic minority health beliefs were open to challenge. Learning from the study: Despite this, some findings were valuable and have considerable potential as a stimulus to critical thinking among practitioners about their own attitudes, as well as raising issues that future research would find it useful to address.
\end{abstract}

Key words: Bangladeshis; black and ethnic minorities; health beliefs; health promotion; nutrition; practice-based research; practice development; reflective practice

Received: 27 February 2008; accepted: 15 May 2008

\section{Introduction}

The NHS rightly lays great emphasis on evidencebased health care. On the one hand, there is a scientific ideal of research evidence, wherein a number of well-conducted large-scale studies identified in a systematic review are combined by meta-analysis to produce robust evidence for achievable changes in practice and service delivery (Sackett and Rosenberg, 1995; Muir Gray, 1997). On the other hand, there is an interest in measuring the effectiveness or appropriateness of health care delivered at a local level, by means of audit and service evaluation.

Practice-based research is often small scale, undertaken to answer local questions. From a formal research perspective such studies, simply

Correspondence to: Stephen Abbott, Research Fellow, City Community and Health Sciences, St Bartholomew School of Nursing and Midwifery, London EC1A 7QN, UK. Email: s.j.abbott@city.ac.uk

(C) 2008 Cambridge University Press because of their scale, do not provide evidence that is robust by the standards of systematic reviews. In any case, the difficulties of carrying out research while also managing large clinical case-loads and without dedicated research time are considerable, while many NHS staff find it difficult to access expert research advice. Thus, many factors may limit the scientific value of local studies.

Sometimes the results of these studies are published; often, they are not. Yet the only justification for troubling research subjects to give their time and efforts is that there may be a benefit to others. There is thus a duty to disseminate research findings, even when these do not meet the highest standards of evidence, provided that there is honesty about research limitations and clarity about the extent to which the findings have value. Within these limits, the potential of such research for developing practice should not be under-estimated: the small research project described in this paper generated important challenges to prevailing local assumptions about local patients and their needs. 
The paper begins with a narrative of the background and development of the project, and a description of the research methods used. This narrative illustrates the difficulties encountered in developing this research and its methodology. It then discusses some of the tensions inherent in the project, and in the circumstances in which it was developed, and how these limited the scope and value of the study. It concludes by highlighting those selected findings that do have a contribution to make both locally and further afield, while acknowledging that great care must be taken to distinguish between data which, in the light of the study's limitations, do and do not have validity.

\section{Development of project}

The research took place in a nurse-led NHS walkin centre (WIC), a primary health care centre which anyone can attend without an appointment and without being registered there as a patient. It is situated in a borough in North East London. Health in the borough is poor (Mindell et al., 2004): morbidity levels are the highest in London for both sexes. One-third of the population is of Bangladeshi origin.

One of the authors (JB), a nurse consultant working at the WIC, was tasked with promoting research and development activity, both to generate relevant and useful research findings, and to build $R \& D$ capacity within the team. Ideas were invited from staff. The research discussed here was suggested by a member of staff who was aware that the Bangladeshi population showed high levels of ill health. She believed that if WIC staff understood more about the health knowledge and beliefs of their Bangladeshi patients, then they could deliver more appropriate and effective health education. She also believed that research was needed if staff were to acquire such understanding.

From 2003 onwards, a number of discussions were held to develop a proposal based on these ideas. A small bursary was successfully obtained from a local primary care R\&D network (the North East London Consortium for Research and Development), which employed another of the authors (SA) to support primary care researchers in North East London. Another author, MD, joined the WIC team at this point, and carried out a literature review with the support of a university librarian and JB.

Because of the busy WIC workload, there was very limited capacity to carry out the research, and this extended the timescale of the project considerably. After a period of inactivity, a decision was made to submit a Research Ethics committee application by a given date. This was achieved: a small questionnaire focusing on health beliefs about healthy food was rapidly developed. Questionnaire development involved some academic input from a dietician, a professor of research, and a research assistant, none of whom had previously been involved in the project. The questionnaire was translated into Bengali by a WIC staff member. Ethics Committee approval was obtained for the study (2006). After a further delay, due to management changes at the WIC, the study was carried out by MD and her receptionist colleagues in 2007 .

It will be evident from this account that the design and development of the research suffered considerably, not only from the inability of researchers to give the project the time it required but also from the lack of a stable research team with the capacity to 'own' the project from first to last. In particular, the development of the questionnaire was too rapid to allow for sufficient debate and reflection on methodological issues.

It is common enough that research projects, large as well as small, are compromised by environmental and organizational pressures. Publications frequently refer to these pressures in passing; one of our purposes here is in recounting both the pressures and the resulting compromises in some detail is to reassure practitioner-researchers whose projects are similarly problematic that they are not alone. But it is also our purpose to show that these compromises have to be taken seriously; as we shall see later, when the scientific data of quality is unsatisfactory, it cannot be treated as valid and robust. On the other hand, where findings do have a contribution to make to knowledge and/or practice development, efforts should be made to disseminate them.

\section{Methods}

The method chosen was the structured questionnaire, administered face-to-face; the interviews were conducted by reception staff, who received 
appropriate training. This provided an opportunity to give them research skills and experience. It also solved potential language problems, since all receptionists were of Bangladeshi origin and could conduct the interviews in Bengali or Sylheti if required (Sylheti is an unwritten dialect variant of Bengali, widely used locally).

The interview was in three sections. The first consisted of some basic demographic questions (gender, age, place of education, length of time living in a high income country, family situation). The second consisted of pictures (with English and Bengali words) of 12 foods: burger and fries, tandoori chicken, salad, ghee, cola, pepper, porridge, gourd curry, yogurt, Asian sweets, cabbage and white rice. Interviewees were asked to say whether each of these foods was healthy or unhealthy, high or low in fat, high or low in sugar, high or low in fibre, and whether they were strong or weak. This latter classification was taken from Greenhalgh et al.'s (1998) work on Bangladeshi folk beliefs about food:

'Strong' foods, perceived as energy giving... health giving and powerful for the healthy body and suitable for festive occasions, but liable to produce worsening of illness in the old or debilitated. 'Weak' foods preferred in the everyday menu and for the old or infirm...

The third section asked whether respondents would like to receive more information about a healthy diet, and if so, via what medium (education session, course, books, leaflets, video, DVD, CDs, tapes, telephone helpline) and in what language (English, Bengali, Sylheti).

Questions generally invited tick-box answers, although there was some space for interviewers to record comments in free text. Because of time constraints, the questionnaire was not piloted.

Time pressures limited the extent of the study: 33 interviews were carried out, although 50 had been intended (a sample size chosen for pragmatic reasons as being likely to be achievable). Four reception staff conducted 16, 12, 4 and 1 interviews, respectively. Bangladeshi patients asking at the WIC reception for a consultation were asked to take part in the research either while they waited to be seen, or immediately afterwards, but this could only be done at relatively quiet times when reception staff were available to conduct the interviews. Sampling was thus necessarily opportunistic: it is not known how this may have skewed the sample (but see section 'Findings'). Written informed consent was obtained by the interviewers at the time of the interview.

The primarily quantitative findings were analysed by MD and SA: free text was coded and turned into quantitative date. Summary rather than inferential statistics were used because of the small sample size and because no power calculation had been carried out. At the analysis stage, it became clear that because the questionnaire had not been piloted, a number of questions were insufficiently precise (eg, not distinguishing lowfat from other yoghurts). Thus, some data could not be interpreted and have been omitted.

The intention was that the research findings would be the subject of education sessions for WIC staff, both in order to share learning about the research process and to disseminate the findings. By the time the project was complete, both $\mathrm{JB}$ and $\mathrm{MD}$ had left the WIC, and R\&D was no longer a managerial priority at the WIC, and this intention was not fulfilled.

\section{Contextualizing the narrative}

The research process described above highlighted four important areas of difficulty:

- finding time for $\mathrm{R} \& \mathrm{D}$ in very busy direct-access health care settings;

- doing good quality research while simultaneously developing research capacity;

- the challenge of health education; and

- the challenge of researching the health of black and minority ethnic (BME) groups.

These will be considered in turn.

\section{Finding time}

In the 1990s, a number of reports highlighted the need to develop primary care R\&D (eg NHS Executive, 1997). As a result, primary care research networks were set up (Thomas and While, 2001): such a network funded the study described here. However, research suggests that nurses working in primary care do not usually have time to do research (Davies et al., 2002). Research like all other activities requires an appropriate level of resourcing, which was not provided by a small 
bursary. During this period, the WIC came under increasing service pressure to meet the $4 \mathrm{~h} A \& E$ waiting target, and consequently nurses and receptionists struggled to find time for the project. For example, the researchers had to rely on some spare university research capacity to complete the Research Ethics committee application.

\section{Good research versus capacity-building}

The tensions between doing good research and building research capacity are substantial (Abbott and Gunnell, 2005). While academic researchers may be experts in research methods, it is counterproductive for them to impose their own research agenda on the primary care staff whom they hope will implement it: it is important to create ownership among those who wish to develop their $R \& D$ capacity. At the same time, it may be that front-line staff wish to prioritize research questions that are in some ways problematic, as in this case. This study was based on an assumption that individual lifestyles are a dominant cause of illness (a view that admittedly was in harmony with the government's own thinking, set out some time later in the White Paper Choosing Health (DH, 2004)). The academic argument against this assumption draws on abundant research evidence suggesting that it is socio-economic status rather than health behaviour that primarily determines health (Davison and Davey Smith, 1995; Marmot, 2004). Health behaviour may be an important means whereby socio-economic status affects health, but it follows that health behaviour is a problem of social structure as well as, or more than, one of individual choices. The research reported here was based on a firm belief that individuals could and should take responsibility for promoting their own health, regardless of their socio-economic status.

Thus, the 'theory of change' (Judge, 2000) underlying the project was questionable. Judge (2000) describes how health care professionals may initiate projects designed to effect or contribute to change without having a clear and evidence-based theory about how the actions they propose will lead by cause and effect to the desired outcome. In this case, various assumptions were made about cause and effect, which existing knowledge does not fully substantiate.
Nevertheless, from the point of view of $R \& D$ capacity-building, the research had the potential to give participants an experience of how the research process can itself develop skills of critical thinking, and challenge underlying assumptions, including those underpinning the research itself. On that basis it was taken forward.

A further challenge arises from the use of WIC staff to carry out the research. Clearly, it is administratively much easier to develop the R\&D capacity of staff in their own workplace, but to do so creates the potential for patients to feel pressure to participate, and/or to make what they take to be the 'right ' answers during the interviews, in order to please those providing the health care they have come to seek. As in this project, scrutiny by a Research Ethics committee and staff training can minimize but not remove such risks.

\section{Health education}

The study arose from the belief that WIC staff could improve the health of their patients if there was a better understanding of those patients' beliefs and knowledge about health. Thus, it was believed that health education was an appropriate and potentially effective strategy for improving local population health and reducing health inequalities.

However, it is not self-evident that WICs are an ideal location for health education. It is true that it is possible to impart simple pieces of information in only a few seconds, and that every health care consultation is an opportunity to do so. But it is also true that the simple passing on of information is in itself rarely effective for many reasons (well summarized in Wanless, 2004, 7.9-7.14), not least the extent, complexity and changing nature of health information and advice. In any case, lack of knowledge about healthy behaviours is not typically the most important cause of unhealthy behaviours: see Hilary Graham's classic study of women who smoked, knowing well the dangers to health of doing so, as a conscious strategy for dealing with difficult circumstances (Graham, 1987).

\section{BME health research}

Health research among BME groups takes place in a historical context of racism and unsound 
research. Such research can be used to reinforce the idea that BME health problems arise primarily from ethnic characteristics (physiological, cultural or behavioural) rather than from the institutional racism of services or the relative deprivation of many BME groups (Bhopal, 1997). Nevertheless, if there are particular needs in any BME groups, then the principle of equity requires that these are addressed, and to do so requires reliable information, whether that be information about genetic predisposition, health behaviours, social exclusion or institutional racism.

The study described here made assumptions that from some perspectives could be judged to be unsound. One assumption was that cultural factors impede healthy eating by Bangladeshis. It is easy for researchers to exaggerate the importance of such factors (Helman, 1990; Lambert and Sevak, 1996), and to ignore factors that go beyond specific BME groups, such as poverty, which is clearly associated with higher rates of unhealthy behaviour. This risks 'victim-blaming', a process by which BME groups and individuals are expected to take responsibility for the ill-health that in fact arises from issues that relate to social structure, such as poverty. As already pointed out, the research took place in a very deprived borough; furthermore, Bangladeshis are the most deprived BME group in Britain (National Statistics, 2003). In such a context, an emphasis on the behaviour of individuals of one ethnicity, instead of on underlying poverty, may be considered to be ill-judged and possibly discriminatory.

There is also a danger, inherent in research into specific BME groups, of assuming that all community members behave in similar ways, thereby stereotyping communities that are diverse and changing. Members of the Bangladeshi community (Hawthorne et al., 2007) may differ from each other in important respects: length of time living in high-income countries and in Bangladesh; whether English- or Bangladesh-educated; degree of fluency in reading, writing and speaking English; preference for traditional or Westernized lifestyles; religion; and so on.

It is interesting that this project was suggested by a staff member from the Bangladeshi community. This shows how racism may not be an adequate explanation for BME research that is stereotyping or victim-blaming. Instead such research may arise from insufficient familiarity with what is already known about BME health, health behaviour and poverty. Projects such as the one reported here have the potential to facilitate critical thinking, when, for example, the results do not confirm the assumptions of practitioners.

\section{Findings}

The above narrative highlights the challenges confronting small projects such as this, and illustrates how those challenges can erode the quality of the resulting research. One response to such erosion is simply not to attempt dissemination of findings. But we have taken a different view, for three reasons, each of which relates to a different aspect of the project: as research, as a contribution to service development and as a capacity-building exercise. Considering the project as research, the only argument for attempting dissemination is the duty already mentioned: there is no ethical justification for troubling patients to take part in research that is given no chance to contribute to knowledge or to influence practice. Considering the study as a project to inform service development, it can be argued that even suggestive but non-robust findings may prompt useful discussion that can help to improve practice. Considering the project as an attempt to enhance R\&D capacity, staff engaging in research for the first time need that engagement to be acknowledged and discussed, rather than remaining invisible; while in any case dissemination is an aspect of $R \& D$ to which they should be being introduced.

As it happens, in the case reported here, some useful messages did emerge. However, it is only legitimate to present such findings if the limitations of the study are made clear and if invalid data are excluded. One purpose of this paper is to show that if data from flawed studies are to be disseminated locally or published, great care must be taken to ensure that no unjustified claims are made for their validity and significance.

Table 1 profiles the 33 respondents. Of these, 12 were men and 21 female. Twenty were aged 30 or under (range $12-30 ; 13$ were 31 or over (range 32-69). Thus, our sample over-represented women and younger patients. Sixteen had been educated in the UK, 10 in Bangladesh, and two elsewhere. Four had lived in a high-income country for three years or less, 11 for between 
Table 1 Summary of respondents

\begin{tabular}{lc}
\hline & Number \\
\hline Gender & \\
Men & 12 \\
Women & 21 \\
Age & \\
$\quad$ Aged 30 or under & 20 \\
Aged 31 or over & 13 \\
Educated & 16 \\
UK & 10 \\
Bangladesh & 2 \\
Other & \\
Time in high income countries & 4 \\
3 years or less & 11 \\
4-20 years & 17 \\
21 years or more & \\
\hline
\end{tabular}

Where numbers in a row do not sum to 33 , this is because of missing data.

4 and 20 years, and 17 for 21 years or more. Thus, those agreeing to be interviewed had typically had considerable time to become acquainted with majority cultural habits in the UK, and were not fully representative of the local population.

Over $90 \%$ thought that salad and cabbage are healthy, and $75 \%$ or more thought that burger and fries, ghee, cola and Asian sweets are not. Over $90 \%$ said that burger and fries, ghee and Asian sweets are high in fat, and that salad and cabbage are low.

Respondents were more confused about sugar, with only $64 \%$ thinking that salad is low in sugar and only $49 \%$ thinking that cabbage is. The high rate of Don't Know for questions about fibre, except in the case of salad and cabbage, suggests a lack of understanding of this particular aspect of food. (Data on other foods have been excluded because the validity of the questions is doubtful, as illustrated above in relation to yogurt.)

Thus, respondents seem to have grasped some 'headlines' about nutrition; this reflects other research findings, such as the second Health and Lifestyles survey, which found that $91 \%$ of Bangladeshis reported understanding what fat is (Johnson et al., 1999). But there is also evidence of a limited grasp of detail. The question arises whether this level of understanding is specific to this ethnic group?

There are no directly comparable studies, but the literature suggests that, regardless of ethnicity, people in general grasp the 'headlines' without understanding the detail, like our respondents.
Povey et al. (1998) found that though Australian women do not primarily think in terms of nutritional groups, there was an awareness that sugar and fat were potentially unhealthy. Buttriss (1997) found that a nationally representative UK sample were poor at recognizing foods containing fibre, though they recognized that fat and sugar were unhealthy. Hankey et al. (2003), Barratt (2001) and Dibsdall et al. (2002) all found that a grasp of nutritional detail was poor even among health professionals. Coveney (2004) and Buttriss (1997) found that poorer populations were less likely to have such a grasp, and although our study did not ask about affluence and deprivation, it is reasonable to assume a degree of deprivation in most cases, given the poverty of the borough as a whole.

In general, therefore, we did not find evidence to support a belief that, compared with the population in general, the Bangladeshi population in North East London does not understand in broad terms what constitutes healthy eating, This may be a consequence of our sample which was small and not representative. However, even this small sample challenged the widely held local assumption that cultural factors are important in explaining BME health (Helman, 1990; Lambert and Sevak, 1996). Other local research shows that that cultural assumptions about health behaviours are to be found among a wide range of primary care health professionals in North East London (Abbott and Riga, 2007). There is thus scope for using findings such as these among NHS staff locally to stimulate debate with a view to challenging such tacit assumptions. It is clear, however, that this study in itself cannot offer an authoritative evidence-based alternative to such assumptions.

A second useful finding from our study is that the categories of 'strong' and 'weak' food were not understood by many of those interviewed. The rate of Don't Know for these questions was much higher than for other questions, across all 12 foods, and in 16 cases (nearly half), interviewers recorded in free text that the interviewee did not understand the term. As already stated, these terms were taken from Greenhalgh et al.'s (1998) study of the folk beliefs of predominantly first generation Bangladeshis. The fact that our sample included many who were educated in and/ or had lived in high income countries for many 
years may be sufficient explanation of the difference between the two studies. Thus, it seems that BME communities are not homogeneous in their attachment to 'folk beliefs'. This finding is a potentially useful contribution to future studies of Bangladeshi knowledge and beliefs about food, which may wish to explore the usefulness of these categories further at pilot stage before deciding whether to use them.

\section{Conclusion}

The desire to do this small exploratory study developed from an interest expressed both by nursing and receptionist colleagues at the Walk in Centre to be involved in the research process. Some of the findings from the study call into question tacit assumptions and knowledge of health care providers (in the first case) and previous research findings (in the second).

As already described, the local dissemination strategy is likely to remain unimplemented, due to personnel and management changes. As a means of facilitating a debate among health care staff in the WIC about their own assumptions about Bangladeshi health beliefs and cultural homogeneity, the selected and very provisional findings highlighted in this paper could play a useful part. Similarly, it could be used as a vivid example of how much care needs to be taken in planning and conducting research to produce valid results. Self-evidently, this project illustrates the need for adequate resources and preparation time, and how the lack of these compromises research quality. That this study did generate some useful findings may be seen as fortunate, but a fortunate outcome in no way negates its flaws. Those attempting small local research projects should think carefully about time, capacity and continuity from the outset.

Though the implicit claim of the evidencebased health care movement is that robust knowledge is achievable, local research may have to understand its role in contributing to knowledge in more intermediate terms, as dialogue and debate. It is hoped that by exploring the strengths and limitations of building research capacity in local practice settings, this article will help researchers to derive maximum utility from research projects that are similarly constrained, without claiming an inappropriate level of scientific robustness.

\section{Acknowledgements}

We are grateful to the patients for giving their time to be interviewed. We thank all the staff at the Walk-in Centre for their patience and interest, and in particular the following: Afia Khatun Ali, Aysha Begum, Roksana Begum, Fahana Chowdury, Helen Davies, Susie Hannah and Nunu Miah. We are also grateful to Dr Clare Grace, Valentina Lichtner and Ambi Nijjar. The research was funded by the North East London Consortium for Research and Development. The comments of peer reviewers were helpful in improving the paper.

\section{References}

Abbott, S. and Gunnell, C. 2005: Developing R\&D capacity in primary care nursing: report of a research project. Primary Care Research and Development 6, 95-100.

Abbott, S. and Riga, M. 2007: Delivering services to 'the Bangladeshi community': the views of health care professionals in East London. Public Health 121, 935-41.

Barratt, J. 2001: Diet-related knowledge, beliefs and actions of health professionals compared with the general population: an investigation in a community Trust. Journal of Human Nutrition and Dietetics 14, 25-32.

Bhopal, R. 1997: Is research into ethnicity and health racist, unsound, or important science? BMJ 314, 1751-756.

Buttriss, J.L. 1997: Food and nutrition: attitudes, beliefs, and knowledge in the United Kingdom. American Journal of Clinical Nutrition 65, 1985S-995S.

Coveney, J. 2004: A qualitative study exploring socioeconomic differences in parental lay knowledge of food and health: implications for public health nutrition. Public Health Nutrition 8, 290-97.

Davies, J., Heyman, B., Bryar, R., Graffy, J., Gunnell, C., Lamb, B. and Morris, L. 2002: The research potential of practice nurses. Health and Social Care in the Community $10,370-81$.

Davison, C. and Davey Smith, G. 1995: The baby and the bath water. Examining socio-cultural and free-market critiques of health promotion. In Bunton, R., Nettleton, S. and Burrows, R., editors, The sociology of health promotion. Critical analyses of consumption, lifestyle and risk. London: Routledge.

DH (Department of Health) 2004: Choosing health. Making healthy choices easier. London: Department of Health/HM Government.

Primary Health Care Research \& Development 2008; 9: 191-198 
Dibsdall, L.A., Lambert, N. and Frewer, L.J. 2002: Using interpretative phenomenology to understand the foodrelated experiences and beliefs of a select group of lowincome UK women. Journal of Nutrition, Education and Behaviour 34, 298-309.

Graham, H. 1987: Women's smoking and family health. Social Science and Medicine 25, 47-56.

Greenhalgh, T., Helman, C. and Chowdhury, A.M. 1998: Health beliefs and folk models of diabetes in British Bangladeshis: a qualitative study. BMJ 316, 978-83.

Hankey, C.R., Eley, S., Leslie, W.S., Hunter, C.M. and Lean, M.E.J. 2003: Eating habits, beliefs, attitudes and knowledge among health professionals regarding the links between obesity, nutrition and health. Public Health Nutrition 7, 337-43.

Hawthorne, K., Pill, R., Chowdhury, J. and Prior, L. 2007: Understanding family, social and health experience patterns in British Bangladeshi families: are people as diverse as they seem? Primary Health Care Research and Development 8, 333-42.

Helman, C. 1990: Cultural factors in health and illness. In McAvoy, B.R. and Donaldson, L.J., editors, Health care for Asians. Oxford: Oxford University Press.

Johnson, M.R.D., Owen, D. and Blackburn, C. 1999: Black and minority ethnic groups in England: the second Health and Lifestyles survey. London: Health Education Authority.

Judge, K. 2000: Testing evaluation to the limits: the case of English Health Action Zones. Journal of Health Services Research and Policy 5, 3-5.

Lambert, H. and Sevak, L. 1996: Is 'cultural difference' a useful concept? Perceptions of health and the sources of ill health among Londoners of South Asian origin.
In Mant, D., editor, 1998: $R \& D$ in primary care. London: Royal College of General Practitioners.

Marmot, M. 2004: Status syndrome. How your social standing directly affects your health and life expectancy. London: Bloomsbury.

Mindell, J., Fitzpatrick, J. and Seljimani, F. 2004: Health inequalities in London, life expectancy and mortality, 1998-2002. London: London Health Observatory.

Muir Gray, J.A. 1997: Evidence-based healthcare: how to make health policy and management decisions. Edinburgh: Churchill Livingstone.

National Statistics. 2003: Distribution of equivalised disposable income: by ethnic group of head of household, 2000/01. www.statistics.gov.uk/StatBase/datasettype.asp?vink $=6251 \&$ Pos $=4 \&$ ColRank $=2 \&$ Rank $=272$.

NHS Executive. 1997: R\&D in Primary Care. National Working Group Report. London: Department of Health.

Povey, R., Conner, M., Sparks, P., James, R. and Shepherd, R. 1998: Interpretations of healthy and unhealthy eating, and implications for dietary change. Health Education Research $13,171-83$.

Sackett, D.L. and Rosenberg, W.M.C. 1995: The need for evidence-based medicine. Journal of the Royal Society of Medicine 88, 620-24.

Thomas, P. and While, A. 2001: West London Research Network. Increasing research capacity and changing the culture of primary care towards reflective inquiring practice: the experience of the West London Research Network. Journal of Interprofessional Care 15, 133-39.

Wanless, D. 2004: Securing good health for the whole population. Final Report. London: HM Treasury. 